\title{
Counter equatorial electrojet and overshielding after substorm onset: Global MHD simulation study
}

\section{AUTHOR(S):}

Ebihara, Y.; Tanaka, T.; Kikuchi, T.

\section{CITATION:}

Ebihara, Y....[et al]. Counter equatorial electrojet and overshielding after substorm onset: Global MHD simulation study. Journal of Geophysical Research: Space Physics 2014, 119(9): 7281-7296

ISSUE DATE:

2014-09-16

URL:

http://hdl.handle.net/2433/198573

RIGHT:

C2014. American Geophysical Union. 


\section{QAGUPUBLICATIONS}

\section{Journal of Geophysical Research: Space Physics}

\section{RESEARCH ARTICLE \\ 10.1002/2014JA020065 \\ Counter equatorial electrojet and overshielding after substorm onset: Global MHD simulation study}

Key Points:

- Counter equatorial electrojet appears in MHD simulation after substorm

- Separation between Region 2 current and auroral oval results in overshielding

- Inner magnetosphere is constrained by the overshielding after substorm

\section{Correspondence to:}

Y. Ebihara,

ebihara@rish.kyoto-u.ac.jp

\section{Citation:}

Ebihara, Y., T. Tanaka, and T. Kikuchi (2014), Counter equatorial electrojet and overshielding after substorm onset: Global MHD simulation study, J. Geophys. Res. Space Physics, 119, 7281-7296, doi:10.1002/2014JA020065.

Received 8 APR 2014 Accepted 20 AUG 2014 Accepted article online 25 AUG 2014 Published online 16 SEP 2014

\author{
Y. Ebihara' ${ }^{1}$ T. Tanaka ${ }^{2}$, and T. Kikuchi ${ }^{3}$ \\ ${ }^{1}$ Research Institute for Sustainable Humanosphere, Kyoto University, Kyoto, Japan, ${ }^{2}$ International Center for Space Weather Science \\ and Education, Kyushu University, Fukuoka, Japan, ${ }^{3}$ Solar-Terrestrial Environment Laboratory, Nagoya University, Nagoya, Japan
}

Abstract By performing a global magnetohydrodynamic (MHD) simulation, we have demonstrated for the first time that an electrojet at the dayside magnetic equator can be reversed and an overshielding condition can be established in the inner magnetosphere after substorm onset without northward turning of the interplanetary magnetic field. Near the substorm onset, the plasma pressure is highly enhanced in the inner magnetosphere on the nightside. The Region 2 field-aligned current diverges from the diamagnetic current on the surface of the dayside extension of the high-pressure region, which is connected to the ionosphere in the relatively low-conductivity region a few degrees equatorward of the main auroral oval that is formed as the projection of the plasma sheet. The separation of the equatorward boundary of the auroral region and the equatorward boundary of the Region 2 current results in dusk-dawn electric fields that generate a counter electrojet (CEJ) at the dayside magnetic equator. Poleward electric fields in a narrow latitudinal width, which may be regarded as subauroral ion drift and subauroral polarization stream, are simultaneously intensified. The dusk-dawn electric fields may propagate to the inner magnetosphere along a field line as shear Alfvén waves. Then, the inner magnetosphere is completely constrained by the overshielding condition. The intensity and polarity of the CEJ depend largely on at least the ionospheric conductivity that is related to the plasma pressure (probably associated with diffuse aurora). This may explain the observational fact that overshielding does not always occur after onset.

\section{Introduction}

In 1922, Dr. Alvin G. McNish discovered that the $H$ component of the Earth's magnetic field disturbance is abnormally large at Huancayo and that the electric current is concentrated near the magnetic equator [Egedal, 1947]. Chapman [1951] suggested calling such a concentrated electric current an electrojet. He also introduced the terms auroral electrojets and equatorial electrojets, which are hereafter referred to as AEJ and EEJ, respectively, in this paper. Hirono [1950] calculated the ionospheric conductivity, and he explained the formation of the EEJ in terms of polarization by the Hall current that flows vertically near the dip equator. Hirono [1950, 1952] applied the Sq (solar quiet) dynamo theory, which predicts the presence of an eastward EEJ on the dayside. Subsequently, various studies have focused on the driving mechanisms underlying quasisteady and temporally varying equatorial electrojets. These studies are mainly categorized into two groups. The first set of studies bases the origin of the EEJ in the general wind circulation of the neutral atmosphere, while the second set of studies bases the EEJ origin in the polar region-equatorial region electrical coupling.

Richmond and Matsushita [1975] developed a 2-D computer model to simulate the propagation of neutral winds and temperature in the thermosphere. In the simulation, for a given set of ionospheric heating conditions at the auroral latitudes, gravity waves propagated poleward and equatorward with a speed of $750 \mathrm{~m} / \mathrm{s}$, and reached the equator after an elapsed time of about $3 \mathrm{~h}$. By extending the abovementioned model, Blanc and Richmond [1980] demonstrated the presence of a current vortex opposite to that expected from the Sq dynamo theory. This vortex is called the disturbance dynamo. The westward electric field (current) appears at the dayside equator, and the eastward electric field (current) at the nightside equator. A steady state circulation was not achieved even after the $12 \mathrm{~h}$ of simulation, thereby indicating very large timescales of propagation.

The variation in the EEJ is known to be almost simultaneous with the worldwide ground magnetic field variations and solar wind variations [Nishida and Jacobs, 1962; Nishida, 1968; Fejer et al., 1979; Gonzales et al., 1979; Somayajulu et al., 1987; Kikuchi et al., 1996, 2000a, 2000b, 2010; Sastri et al., 1997; Kobea et al., 1998, 2000; Huang et al., 2005; Ohtani et al., 2013]. The near-instantaneous, worldwide variations in the ground magnetic field are not fully explained by the disturbance dynamo because of its slow propagation speed. 
To explain the near-instantaneous, worldwide nature of the ground magnetic field variations, the presence of rapid propagation modes in the Earth-ionosphere waveguide has been suggested by Kikuchi and Araki [1979] (readers may refer to Kikuchi [2014] for a detailed explanation). The electromagnetic waves that are excited by a pair of field-aligned currents (FACs) propagate horizontally at the speed of light. Over time, quasi-steady ionospheric currents are achieved with a time constant range of 1-10 s [Kikuchi, 2014], which should be equivalent to that obtained by solving the elliptic differential equation for current continuity [Maekawa and Maeda, 1978; Nopper and Carovillano, 1978; Tsunomura and Araki, 1984; Tsunomura, 1999].

The global distribution of the ionospheric currents depends entirely on FACs. Two types of large-scale FACs are known to coexist [e.g., Zmuda and Armstrong, 1974]. The poleward pair of large-scale FACs is called the Region 1 current, and the equatorward one is called the Region 2 current [lijima and Potemra, 1976]. On average, the total magnitude of the Region 1 current is larger than that of the Region 2 current. The dominance of the Region 1 current results in the two-cell pattern of large-scale ionospheric convection or the ionospheric Hall current known as the DP2 current system [Tanaka, 1995] because positive (negative) charge is deposited by the Region 1 current flowing into the dawnside ionosphere (out of the duskside ionosphere). The dominance of the Region 1 current may favor an eastward electric field on the dayside, that is, the flow of an eastward Pedersen current at the magnetic equator on the dayside. Because of polarization by the Hall current at the magnetic equator, the zonal current is intensified, which is probably observable as an eastward EEJ.

Observations have shown that the direction of the EEJ is sometimes reversed, which is called a counter electrojet (CEJ). The appearance of the CEJ is most likely caused by a westward Pedersen current (westward electric field) at the magnetic equator on the dayside. The westward electric field can be attributed to either the disturbance dynamo or the overshielding condition. In particular, the CEJs that appear immediately after a drastic change in interplanetary space or the polar region are thought to be caused by the overshielding condition [e.g., Fejer et al., 1979; Gonzales et al., 1979; Kelley et al., 1979; Kikuchi et al., 2000a, 2000b, 2003, 2010; Hashimoto et al., 2011]. At least two drastic changes are thought to be associated with CEJs.

The first drastic change that may cause CEJs is an abrupt northward turning of the interplanetary magnetic field (IMF) after the prolonged exposure of southward IMF. When the IMF turns northward abruptly after the prolonged southward IMF, the Region 1 current starts to decrease abruptly, whereas the Region 2 current decreases gradually [e.g., Spiro et al., 1988; Goldstein et al., 2002; Ebihara et al., 2008; Wei et al., 2008; Kikuchi et al., 2010]. The gradual decrease in the Region 2 current may originate from the fact that the asymmetric ring current, which is one of the most significant generators for the Region 2 current, cannot disappear rapidly. When the IMF turns northward, the asymmetric ring current becomes more symmetric as the ions constituting the asymmetric ring current drift westward in a timescale of a few hours [e.g., Ebihara and Ejiri, 2000; Liemohn et al., 2001]. The timescale for decay of the ring current is longer than several hours, so that the ring current cannot decay rapidly [e.g., Fok et al., 1995; Kozyra et al., 1998b; Liemohn et al., 1999]. Fujita et al. [2010] have demonstrated that the overshielding condition can be established after the northward turning of the IMF because of the generation of a new dynamo on the dayside at the off-equator.

The second one is a substorm onset [e.g., Gonzales et al., 1979; Kikuchi et al., 2000b, 2003; Sastri et al., 2001, 2003; Wei et al., 2009; Hashimoto et al., 2011]. Wei et al. [2009] and Hashimoto et al. [2011] demonstrated that the overshielding condition is clearly achieved after a substorm onset without northward turning of the IMF. Wei et al. [2009] argued two possible mechanisms. The first one is the contraction of the polar cap as suggested by Ebihara et al. [2008]. Wei et al. excluded this mechanism because the electric field associated with the Region 2 current is not increased by the contraction of the polar cap. The second one is the reconfiguration of the near-Earth magnetosphere during the substorm expansion. Wei et al. [2009] suggested that a dawnward facing potential electric field is established in the course of the dipolarization. The dawnward potential electric field propagates to the ionosphere, thereby resulting in a westward EEJ. By incorporating low-entropy flux tubes into Rice Convection Model, Zhang et al. [2009] obtained the simulation result that the overshielding condition can be established just after substorm onset. They suggested the importance of the Region 2 current associated with the incoming low-entropy flux tubes. In their simulation, the $Z$ component of the IMF was, however, near zero, and the polar cap potential that was imposed to their outer boundary was less than $30 \mathrm{kV}$ before and after the onset. The polar cap potential that they used seems to be too low to reasonably explain the overshielding condition taken place under the sustained southward IMF [e.g., Wei et al., 2009; Hashimoto et al., 2011]. 
Thus far, two fundamental questions remain to be answered. The first question concerns why the CEJ occurs immediately after a substorm onset without the apparent northward turning of the IMF (under the sustained southward IMF). The second question concerns what determines the polarity of the EEJ during substorms. The second question arises from the observational fact that a CEJ is not always observed during substorms [Sastri et al., 2001; Huang et al., 2004]. The purpose of this study is to attempt answering these two questions by performing a global MHD simulation that takes into account the coupling between the solar wind, magnetosphere, and ionosphere.

\section{Simulation}

We used the latest version of the global magnetohydrodynamics (MHD) simulation originally developed by Tanaka [1994, 1995, 2000a, 2000b, 2007] and Tanaka et al. [2010]. The simulation utilizes a finite volume total variation diminishing scheme to enable adequate capture of a shock. The present simulation employs the grid system based on a dodecahedron [Moriguchi et al., 2008]. In the simulation, at the inner surface of the magnetosphere, a given sphere is divided into 12 pentagons. Each pentagon is divided into five triangles (Level 1). Each triangle is further divided into four triangles (Level 2). In the present simulation, we divided each pentagon into 5120 triangles (Level 6), that is, 61,440 triangles in total, corresponding to 30,722 grid points on a sphere. Triangular prisms are stacked outward. The direction of the stacking is skewed so as to concentrate the grid points near the current sheets on the nightside. We stacked 320 segments outward from the inner boundary of the magnetosphere domain located at 2.6 Re. The advantage of this grid system is that there is no singular point.

The inner boundary of the magnetosphere domain is connected with the ionosphere surface by assuming a dipole magnetic field. We calculated the ionospheric electric potential [e.g., Tanaka, 1994] for given fieldaligned current with the ionospheric conductivity. Assuming that the ionospheric horizontal current flows in a thin shell, the ionospheric current is given by

$$
\mathbf{J}=\sum \mathbf{E}=-\left(\begin{array}{cc}
\sum_{\theta \theta} & \sum_{\theta \phi} \\
-\sum_{\theta \phi} & \sum_{\phi \phi}
\end{array}\right) \nabla \Phi_{i},
$$

where $\mathbf{J}$ is the current density, $\Sigma$ is the height-integrated conductivity tensor, $\mathbf{E}$ is the electric field, and $\Phi_{\mathrm{i}}$ is the electric potential at the ionospheric altitude. We assumed that the height-integrated conductivity consists of three sources. The first source is the conductivity associated with the ionization due to solar EUV. We used a functional form depending on the solar zenith angle. The second one is proportional to the field-aligned current density. The contribution from the downward field-aligned current is assumed to be 10 times lower than that from the upward field-aligned current. The third one is proportional to the square root of plasma pressure and to the temperature of magnetospheric plasma to the power of 1/4.

Following the study by Tsunomura [1999], we assumed that the conductivity terms obey the following functions.

$$
\begin{aligned}
& \sum_{\theta \theta}=k_{1}(\lambda) \frac{\sigma_{0} \sigma_{1}}{\sigma_{1} \cos ^{2} I+\sigma_{0} \sin ^{2} I}, \\
& \sum_{\theta \phi}=k_{2}(\lambda) \frac{\sigma_{0} \sigma_{2} \sin I}{\sigma_{1} \cos ^{2} I+\sigma_{0} \sin ^{2} I}, \\
& \sum_{\phi_{\phi}}=k_{3}(\lambda) \frac{\sigma_{1} \sigma_{0} \sin ^{2} I+\left(\sigma_{1}{ }^{2}+\sigma_{2}{ }^{2}\right) \cos ^{2} I}{\sigma_{1} \cos ^{2} I+\sigma_{0} \sin ^{2} I}
\end{aligned}
$$

where $/$ is the inclination of the magnetic field, $\sigma_{1}$ is the Pedersen conductivity, $\sigma_{2}$ is the Hall conductivity, and $\sigma_{0}$ is the parallel conductivity that is assumed to be 8 . The amplification factors, $k_{1}, k_{2}$, and $k_{3}$, depend on latitude $\lambda$, so as to represent large height-integrated conductivities near the equator.

The tilt angle with respect to the solar wind velocity is zero. We introduced a step function at the simulation boundary upstream in the solar wind as follows. The $Z$ component of the IMF was changed from $+5 \mathrm{nT}$ to $-5 \mathrm{nT}$. At the same time, the solar wind speed was increased from 372 to $500 \mathrm{~km} / \mathrm{s}$. The solar wind density was set to a constant value of $5 \mathrm{~cm}^{-3}$, and the $Y$ component of the IMF was $2.5 \mathrm{nT}$. The time instant $T=0$ is defined at the moment of the arrival of the southward IMF at the bow shock at the subsolar point. 

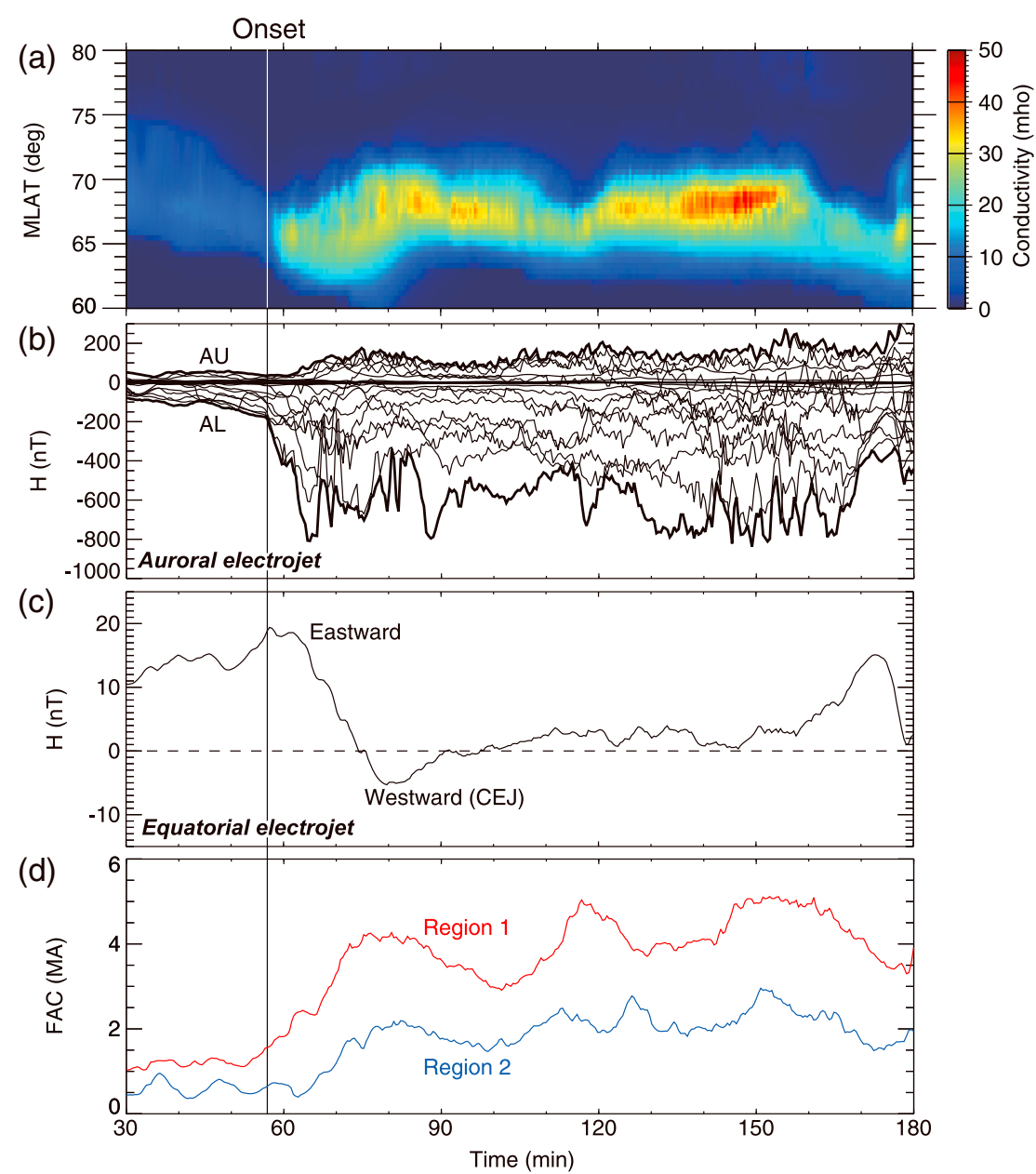

Figure 1. (a) Keogram of the nondiagonal component of the ionospheric conductivity at midnight, (b) north-south component ( $H$ component) of the magnetic field disturbance on the ground at $0,2,4, \ldots$, and 22 MLTs at magnetic latitude of $67^{\circ}$. The upper and lower envelopes of the superposed plots, as indicated by thick lines, correspond to the $A U$ and $A L$ indices, respectively, by definition, (c) north-south component of the magnetic field disturbance at noon at equator, and (d) intensities of the net Region 1 and Region 2 field-aligned currents.

\section{Results}

Figure 1a shows the diagram of the nondiagonal component of the ionospheric conductivity [e.g., Tsunomura and Araki, 1984; Tsunomura, 1999] as a function of the magnetic latitude (MLAT) and time at magnetic midnight. The ionospheric conductivity may be used as a substitute for auroral brightness. The vertical line indicates a substorm onset at $T \approx 57 \mathrm{~min}$. The onset was determined based on the sudden increase in the conductivity around 65-67 MLAT in the premidnight sector (not shown). In Figure 1b, the north-south component ( $H$ component) of the ground magnetic disturbance at 24 magnetic local times (MLTs) at 67 MLAT is shown. The magnetic disturbance is calculated from the Hall current flowing in the ionosphere.

Consequently, 24 corresponding magnetic disturbance lines are overlaid in Figure 1b. The upper and lower envelopes may be regarded as the $A U$ and $A L$ auroral electrojet indices, respectively [Davis and Sugiura, 1966]. The $A L$ index suddenly decreases at $T \approx 57 \mathrm{~min}$, which is consistent with the sudden "brightening" of the aurora. Figure $1 \mathrm{c}$ shows the $H$ component of the ground magnetic disturbance at magnetic noon (12 MLT) at the magnetic equator ( 0 MLAT), which may be regarded as the EEJ. The ground magnetic disturbance at the magnetic equator is calculated from the Pedersen current flowing because of the Cowling effect.

Immediately after the substorm onset, the eastward EEJ gradually decreases. The polarity of the EEJ is reversed from eastward to westward (positive to negative $H$ component magnetic field values) at $T \approx 74 \mathrm{~min}$ (about $17 \mathrm{~min}$ after the substorm onset). The westward EEJ (or CEJ) lasts for about $15 \mathrm{~min}$; and subsequently, the polarity of the EEJ switches from westward to eastward. Figure $1 \mathrm{~d}$ shows the net FACs, and we note that 
(a) Conductivity

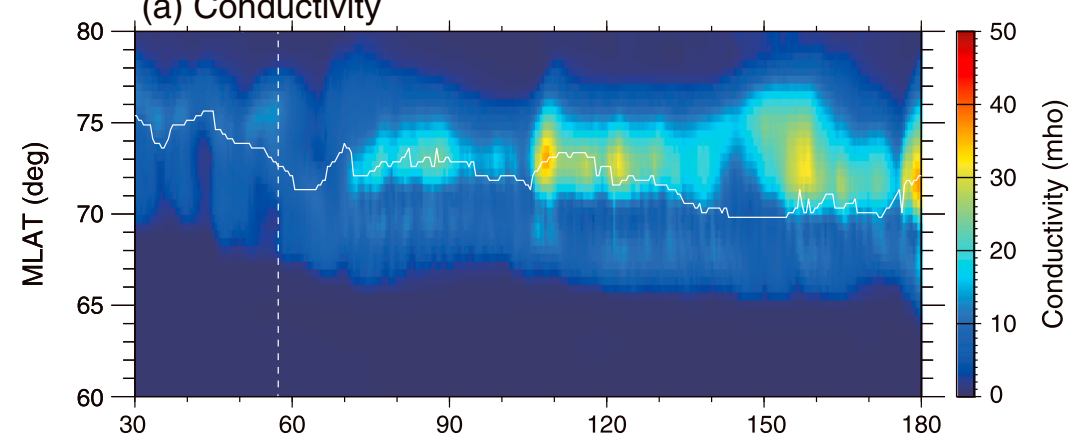

(b) Field-aligned current

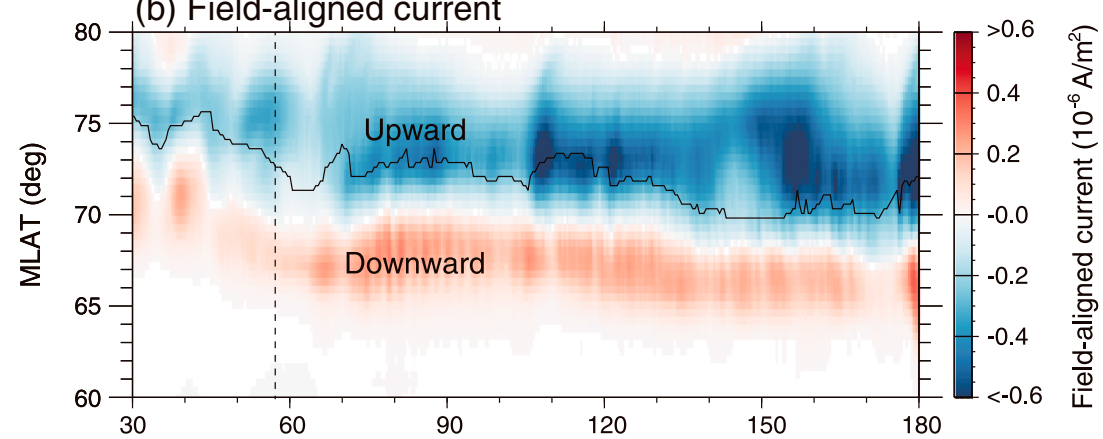

(c) Meridional electric field

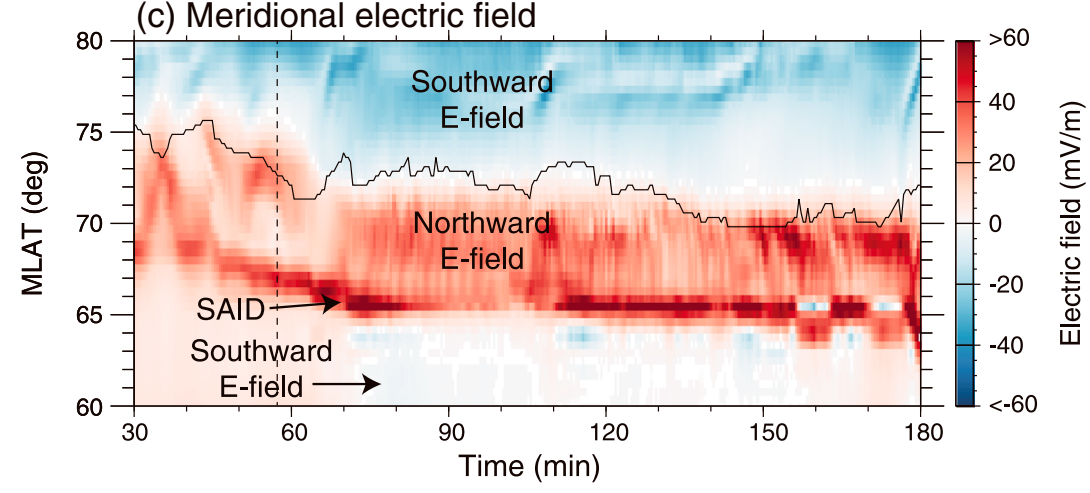

Figure 2. $(\mathrm{a}-\mathrm{c})$ The nondiagonal component of the ionospheric conductivity, field-aligned current, and north-south component of the electric field as a function of magnetic latitude (MLAT) and time at 18 MLT. Lines indicate an open-closed boundary of a magnetic field line. The vertical dashed line indicates the substorm onset.

both the Region 1 and Region 2 FACs increase after onset. The intensity of the Region $1 \mathrm{FAC}$ always dominates that of the Region 2 FAC. We do not focus on the evolution of the substorm since this has already been reported by Tanaka et al. [2010].

Figure 2a shows the nondiagonal component of the ionospheric conductivity. The lower boundary of the auroral region (where the conductivity is high) is shown to range from 65 to 67 MLAT, whereas its upper boundary ranges from 76 to 80 MLAT. The open-closed boundary of the magnetic field lines (as indicated by the jagged line) is located almost at the middle of the auroral region at $18 \mathrm{MLT}$. In Figure 2b, upward and downward FACs are shown to persist, which are consistent with the Region 1 and Region 2 currents, respectively.

Figure $2 \mathrm{c}$ shows the north-south component of the electric field at the ionospheric altitude. In general, the southward electric field occupies the high-latitude region, and the northward electric field occupies the low-latitude region. The southward (northward) electric field corresponds to eastward (westward) plasma flow in the ionosphere. The shear of the plasma flow (and a shear of the Hall current) is located near the open-closed boundary. The northward electric field spreads equatorward until $70 \mathrm{~min}$, which may be regarded as the subauroral polarization stream (SAPS) [Foster and Burke, 2002; Foster and Vo, 2002]. The 


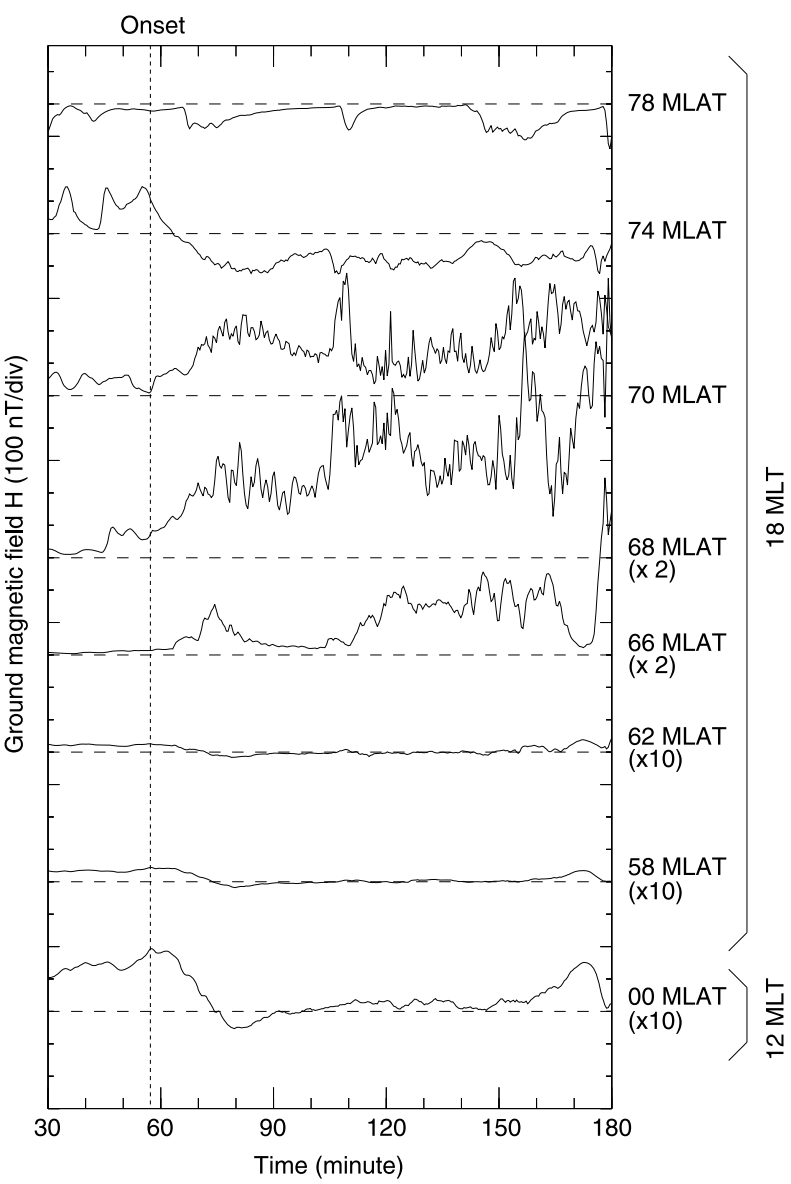

Figure 3. Stack plots of the $H$ component of the magnetic field on the ground at dusk in the polar cap (74 and 78 MLATs), the auroral oval (66, 68, and 70 MLATs), and the subauroral region (58 and 62 MLATs). The bottom line shows the $H$ component of the ground magnetic field at noon at equator. term SAPS has been introduced to encompass a narrow, intense plasma flow and a broad, persistent plasma flow in the subauroral region. The former one is called subauroral electric field (SAEF) [Karlsson et al., 1998] or subauroral ion drift (SAID) [Spiro et al., 1979; Anderson et al., 1993, 2001], which is clearly shown in a latitudinally narrow region between the equatorward edge of the auroral region (Figure $2 \mathrm{a}$ ) and the equatorward edge of the downward FAC (Figure 2b).

There are three remarkable features of interest to be noted immediately after the onset. First, the location of the flow shear moves equatorward from $\sim 76$ to 72 MLAT. This indicates that an observatory located between 72 and 76 MLAT would experience a transition from an eastward plasma flow to a westward one. Second, SAEF or SAID is intensified. The northward electric field exceeds $60 \mathrm{mV} / \mathrm{m}$ in the region between 65 and 66 MLAT, and the thickness of the intensified electric field region is as small as about $1^{\circ}$. The locally intensified electric field persists for a few tens of minutes. The intensification of SAEF or SAID is consistent with observations [Anderson et al., 1993; Karlsson et al., 1998]. Third, from $T \approx 70 \mathrm{~min}$ and onward, a southward electric field appears

equatorward of the SAEF or SAID, which persists for $\sim 1.5 \mathrm{~h}$ intermittently. The southward electric field is most likely associated with the overshielding condition as explained below.

Figures 3 and 4 show the $H$ component of the ground magnetic disturbance $(\Delta H)$ and the electric field, respectively, obtained at $18 \mathrm{MLT}$ except for the bottom one. The bottom one indicates the quantities obtained at 12 MLT at the magnetic equator. The following summarizes the major characteristics of the $\Delta H$ curves.

1. At 78 MLAT, $\Delta H$ shows some negative excursions after the onset around $T \approx 70,110$, and $150 \mathrm{~min}$. The negative excursions are attributed to the poleward expansion of the auroral region together with a slight increase in the southward electric field.

2. At 74 MLAT, the amplitude of $\Delta H$ is larger than that at 78 MLAT because the conductivity is permanently higher than that at 78 MLAT (cf. Figure 2a). The polarity of $\Delta H$ changes from positive to negative about $10 \mathrm{~min}$ after the onset. The transition of the polarity corresponds to the transition of the north-south component of the electric field (cf. Figure 4). Thus, the decrease in $\Delta H$ at 74 MLAT during the expansion phase primarily originates from the equatorward motion of the shear of the Hall current. We may safely state that this location is in the polar cap after the onset because the open-closed boundary is located at a position lower than 74 MLAT after the onset.

3. In the auroral region at 70,68 , and 66 MLATs, $\Delta H$ shows a positive excursion after the onset, which is attributed to the intensifications of both the northward electric field and the conductivity.

4. In the subauroral region at 62 and 58 MLATs, $\Delta H$ shows a negative excursion, which is opposite to that in the auroral region. The negative excursion of $\Delta H$ is due to the southward electric field in the 


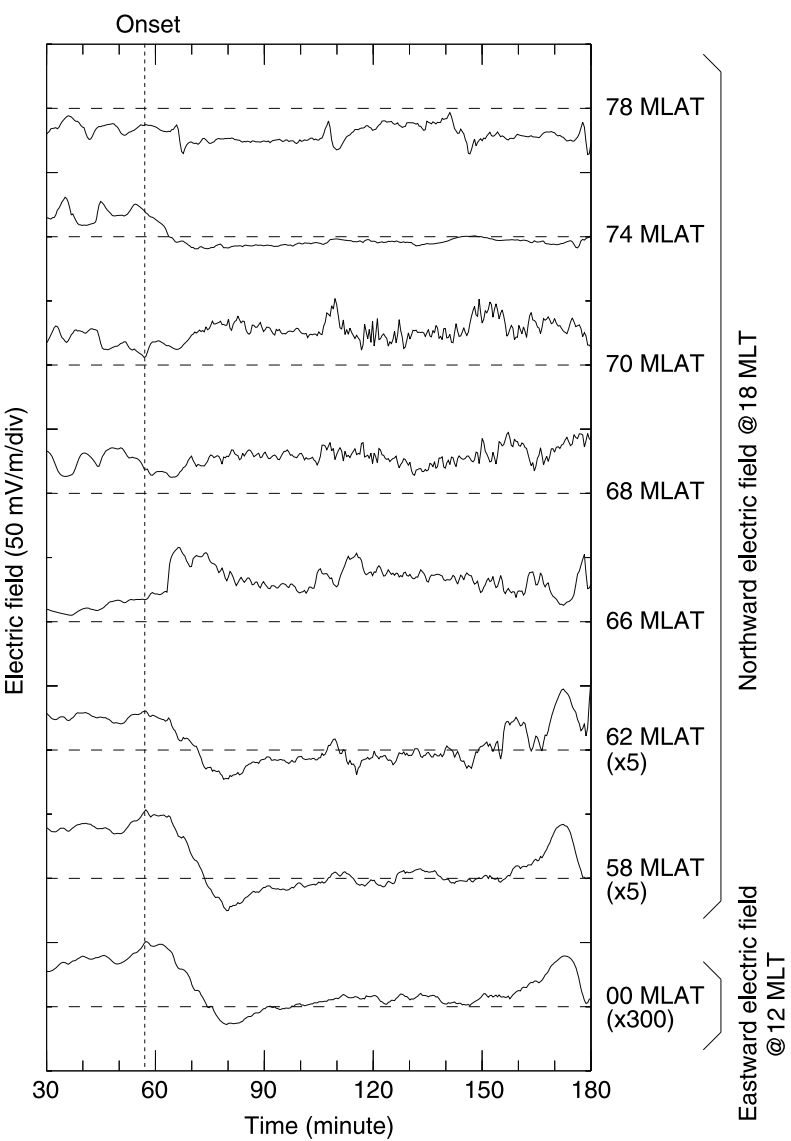

Figure 4. Same as Figure 3 except for electric field. The northward electric field is shown at MLATs from 58 to 78 MLATs, and the eastward electric field is shown at 00 MLAT at noon. subauroral region, as shown in Figure 4. No significant upward FAC appears equatorward of the downward FAC, as can be observed from Figure $2 \mathrm{~b}$. Thus, the southward electric field is not simply attributed to the immediate current closure of the downward FAC at higher latitudes and the upward FAC at lower latitudes at the same meridian.

5. At noon at the magnetic equator, $\Delta H$ starts to decrease at the onset, and it shows a negative excursion.

All these characteristics of the $\Delta H$ variations are fairly consistent with the ones presented by Hashimoto et al. [2011] in terms of a negative excursion in the polar cap, a positive excursion in the auroral region, negative excursion in the subauroral region, and a decrease in $\Delta H$ at the dayside magnetic equator.

Figure 5 shows the (a) AEJ, (b) EEJ, (c) FAC, (d) the nondiagonal component of the ionospheric conductivity, (e) plasma pressure mapped from the 2.6 Re surface to the ionosphere altitude together with the electric potential at the ionosphere altitude, and (f) electric potentials down to the equator. Before the onset

( $T=56 \mathrm{~min}$ ), the electric potential exhibits a two-cell-type pattern, namely, a positive potential on the dawnside and a negative one on the duskside. As previously demonstrated by Tanaka [1995], the pattern of the electric potential is consistent with the one observed when the geomagnetic activity is high, or when the IMF is southward [e.g., Axford and Hines, 1961; Nishida, 1966; Heelis et al., 1982; Foster et al., 1986; Heppner and Maynard, 1987; Papitashvili et al., 1994; Rich and Hairston, 1994; Ruohoniemi and Greenwald, 1996; Weimer, 2001]. The pattern of the FAC is consistent with that statistically derived by lijima and Potemra [1976], namely, a pair of Region 1 currents flow in the poleward region, and a pair of Region 2 currents flow in the equatorward region. Immediately after the onset $(T=58 \mathrm{~min}$ ), the FAC, the plasma pressure, and the ionospheric conductivity start to increase near the midnight. At $T=74 \mathrm{~min}$, the plasma pressure is particularly enhanced on the nightside. The FACs are enhanced not only on the nightside but also on the dayside. The electric potential is partly deformed in the subauroral region. At $T=80 \mathrm{~min}$, a negative (positive) electric potential clearly appears in the subauroral region on the dawnside (duskside). The polarity of the newly added potential is opposite to that of the preexisting two-cell-type field pattern. The reversed potential structure appears in the region in which the conductivity is relatively low, and the Region 2 current flows (Figure 5e) and spreads toward the equator (Figure 5f). It is clearly shown that the reversed potential shields the convection electric potential, and that the westward electric field is imposed at the magnetic equator on the dayside, generating the CEJ.

Figure 6 presents a bird's eye view of selected Region 2 currents. Figure $6 a$ shows the current lines extending from near the poleward edge of the Region 2 current. The current lines clearly originate in, or in the vicinity of the high-pressure region indicated by the gray surface. The current lines are almost tangential to the surface of the high-pressure region near the equatorial plane, thereby indicating that the current is dominated by the diamagnetic current near the equatorial plane. The current lines shown in Figure 6a may not significantly contribute to the CEJ because they flow into and out of the auroral region (high-conductivity region). The 


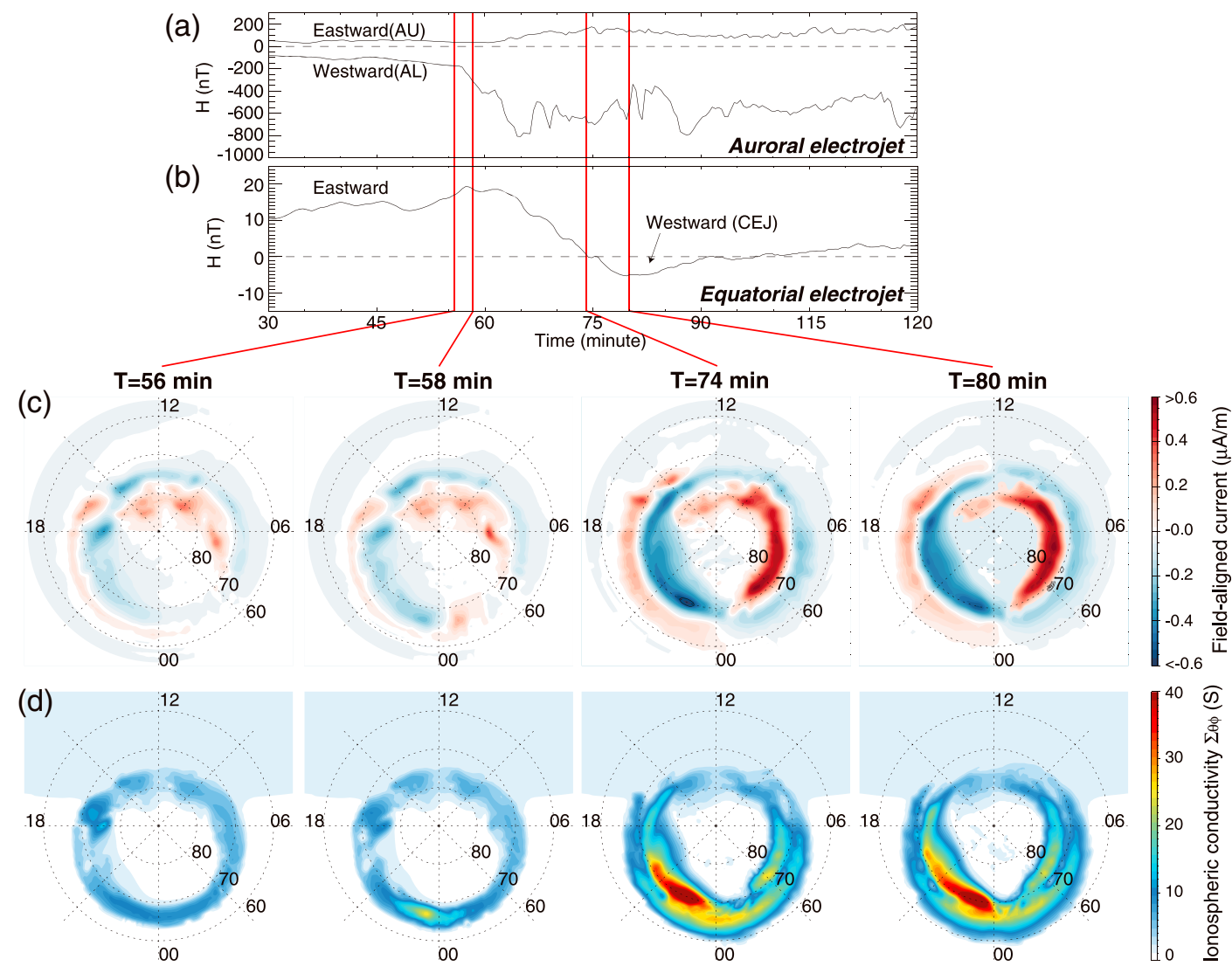

(e)
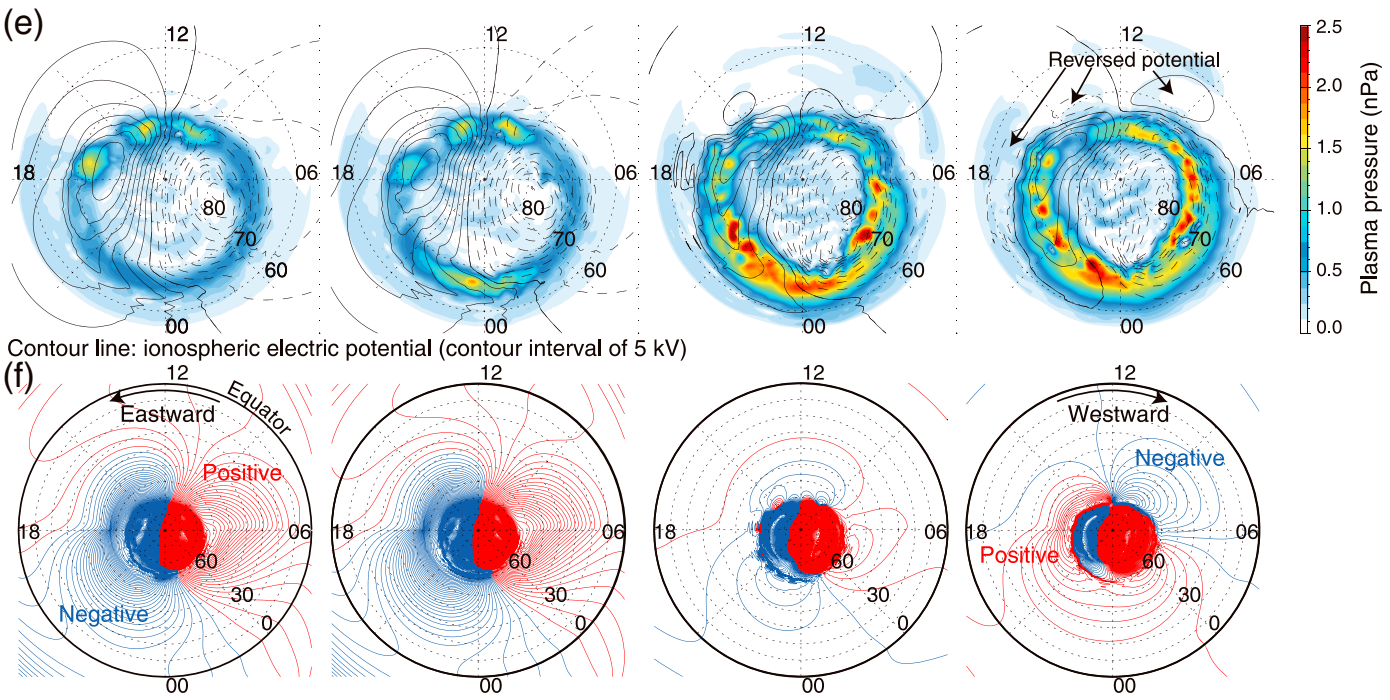

Contour line: ionospheric electric potential (contour interval of $0.5 \mathrm{kV}$ )

Figure 5. (a) $A L$ and $A U$ (auroral electrojet; $A E J$ ) indices, (b) $H$ component of the ground magnetic disturbance at noon at equator (equatorial electrojet; EEJ), (c) the field-aligned current at the ionosphere altitude, (d) the nondiagonal component of the ionospheric conductivity $\Sigma_{\theta \phi}$ (e) the plasma pressure, and (f) the electric potential down to the equator (red for positive and blue for negative potentials). The Sun is to the top. In the Figure 5e, the contour lines indicate the electric potential (positive dashed line and negative solid line).

current lines extending from near the equatorward edge of the Region 2 current and the low-conductivity region (nondiagonal component of the ionospheric conductivity being less than 1 mho) are shown in Figure $6 \mathrm{~b}$. Most of the current lines originate from the dayside because of the strong perpendicular current directed eastward. The color scale of the current line indicates the value of $\mathbf{J} \cdot \mathbf{E}$, where $\mathbf{J}$ is the current density 
(a) Near the poleward edge of Region 2 current

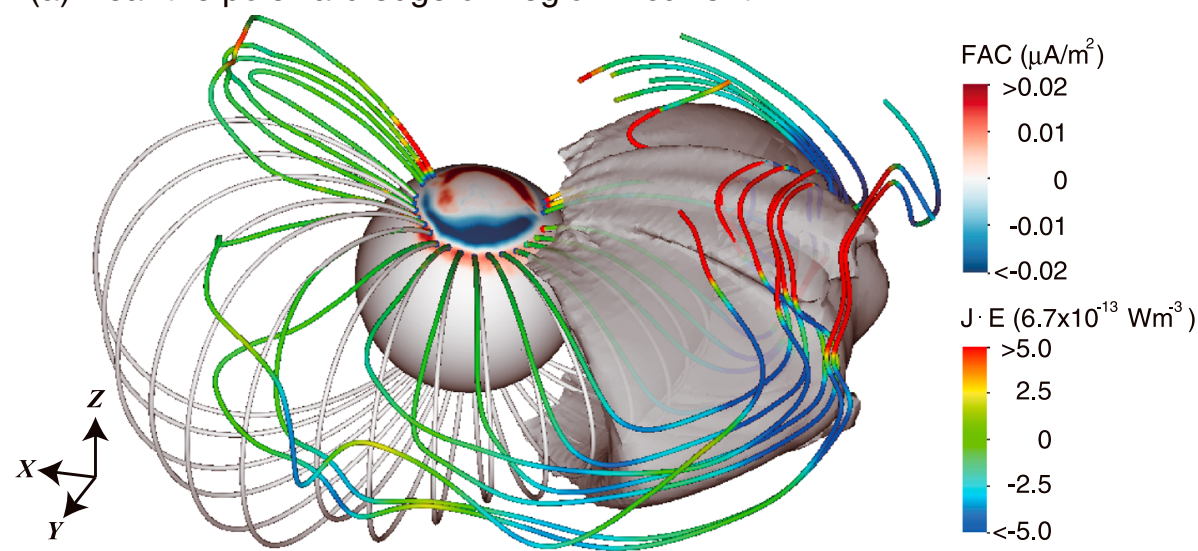

(b) Near the equatorward edge of Region 2 current
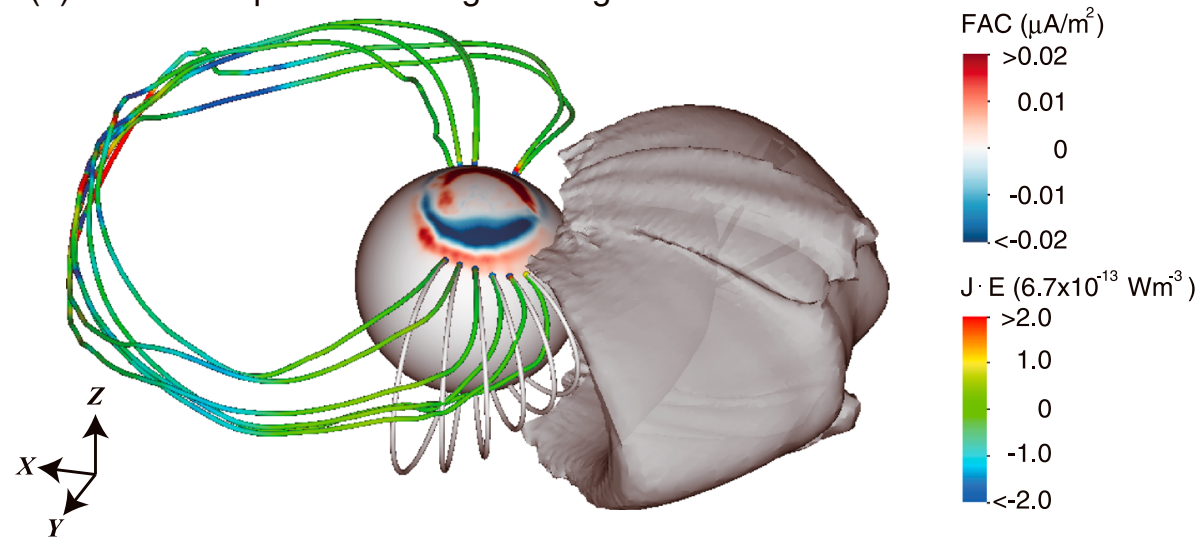

Figure 6. Snapshots of current lines (color lines) and magnetic field lines (gray lines) at $T=80 \mathrm{~min}$. A sphere indicates a surface at geocentric distance of $2.6 \mathrm{Re}$, and the red to blue color codes denote the field-aligned current (FAC) (positive earthward). The gray surface shows a high-pressure region $(>1.2 \mathrm{nPa})$. The color codes of the current lines denote the value of J E. (a) The current lines and the magnetic field lines are extending from near the poleward edge of the Region 2 current on the duskside in the Northern Hemisphere. (b) They are extending from near the equatorward edge of the Region 2 current and the low-conductivity region (nondiagonal component of the ionospheric conductivity being less than 1 mho).

and $\mathbf{E}$ is the electric field. A negative value of this value implies the presence of a generator in which mechanical energy is converted to electrical energy. The generator for these particular current lines is located in the high-pressure region on the dayside. The high-pressure region on the dayside is an extension of that from the nightside, as shown later (Figure 10).

Figure 7 shows an example of the magnetic field lines and a current line at $T=80 \mathrm{~min}$. The magnetic field lines indicated by gray lines are located near the equatorward edge of the high-pressure region. The current line (indicated by the yellow line) is deflected eastward, and it connects with the sphere of 2.6 Re a few degrees equatorward of the footprint of the magnetic field line extending from the inner edge of the highpressure region. There are at least two mechanisms underlying the separation of the Region 2 current and the equatorward boundary of the high-pressure region. First, a strong eastward current (diamagnetic current) is induced in the inner part of the high-pressure region, causing eastward deflection. Second, the inner edge of the high-pressure region is located inward with increasing MLT from dusk to midnight, thereby causing earthward (equatorward) deflection. Because of these two factors, some Region 2 currents flow into the ionosphere equatorward of the equatorward boundary of the high-pressure region, namely, the auroral region on the duskside.

The separation of the equatorward boundary of the Region 2 current and the equatorward boundary of the high-conductivity region is clearly shown in Figure 8. The northward electric field is enhanced in a latitudinally narrow region in the range of 65-66 MLAT, which may correspond to SAID. At low latitudes ( $<64.5 \mathrm{MLAT})$, the electric field is southward, which probably means that the contribution from the positive 


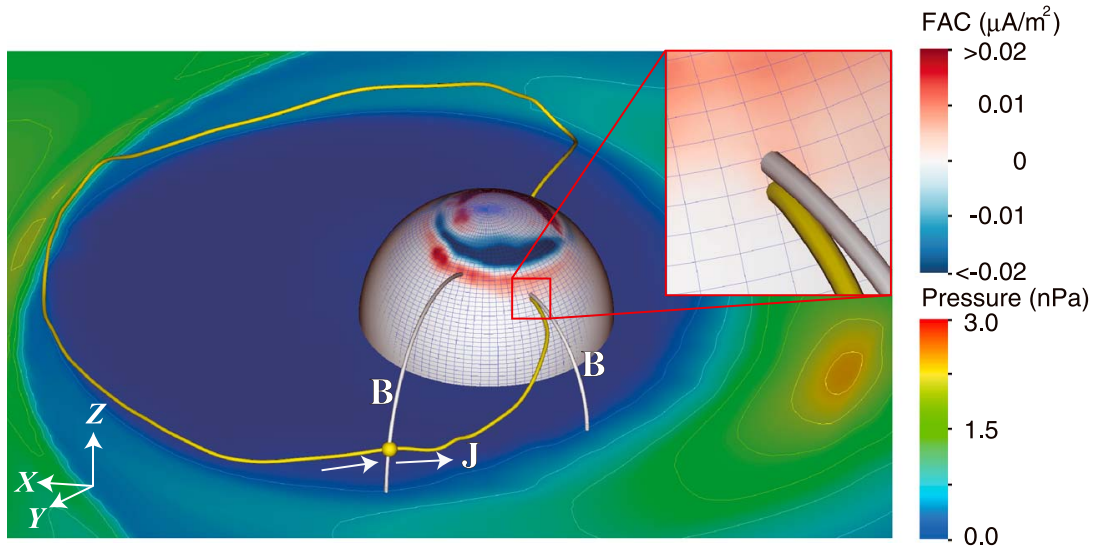

Figure 7. Snapshot of magnetic field lines $\mathbf{B}$ (gray lines) and a current line $\mathbf{J}$ (yellow line) at $T=80 \mathrm{~min}$. The color contour shows the plasma pressure in the equatorial plane. A sphere indicates a surface at geocentric distance of $2.6 R e$, and the red to blue color codes denote the field-aligned current (FAC) (positive earthward).

electric potential brought by the downward Region 2 current dominates that by the upward Region 1 current. Thereby, the electric field is reversed at low latitudes, and the southward electric field is thought to be the cause of the CEJ at dayside magnetic equator.

It is expected that the electric field generated in the ionosphere may propagate upward along a field line because Nishimura et al. [2009] demonstrated that the Poynting flux propagated from the ionosphere to the
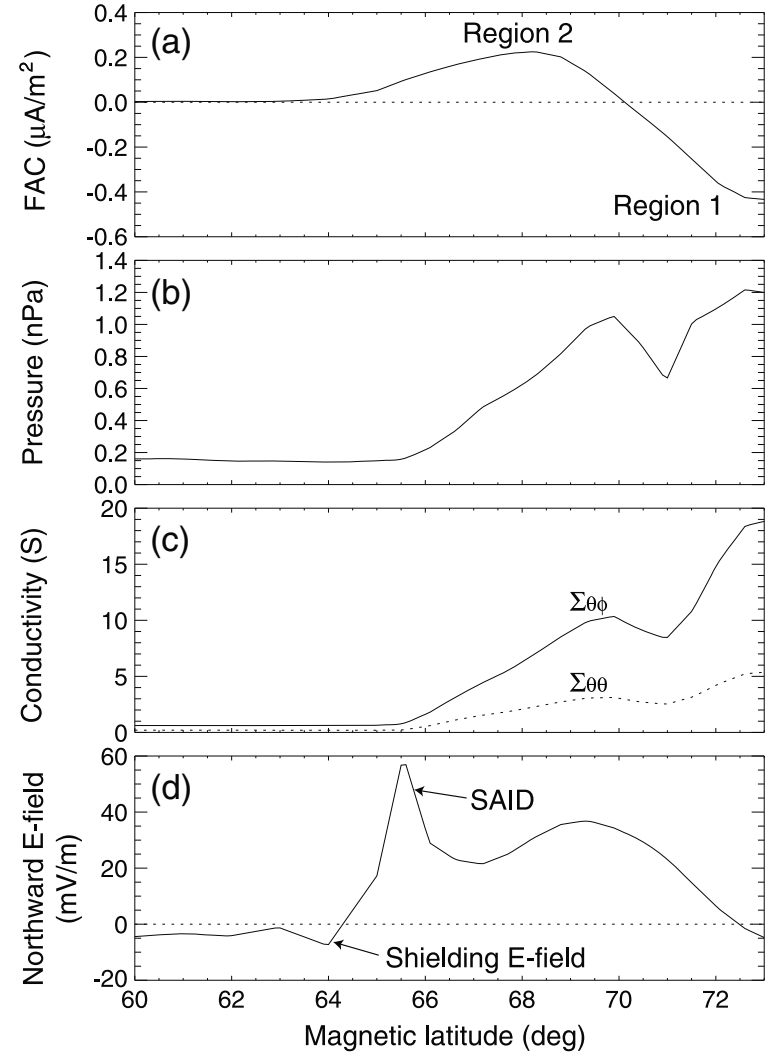

Figure 8. (a) Field-aligned current (positive earthward), (b) plasma pressure, (c) two components of the ionospheric conductivities (solid line for $\Sigma_{\theta \phi}$ and dotted line for $\Sigma_{\theta \theta}$ ), and (d) northward electric field at the ionosphere at $18 \mathrm{MLT}$ at $T=80 \mathrm{~min}$. magnetosphere. Figure 9 shows the $Y$ component of the electric field $\left(E_{y}\right)$ in the noon-midnight meridian. The positive $E_{y}$ corresponds to the two-cell-type convection that typically appears in magnetically active times. The negative value of $E_{y}$, as indicated by the blue color, appears to propagate from the ionosphere to the equatorial plane along a field line in the inner magnetosphere. $E_{y}$ is not symmetric with respect to the equatorial plane because the ionospheric electric potential is not symmetric between the Northern and Southern Hemispheres.

Figure 10 shows the plasma pressure, $E_{y}$, and the intensity of the magnetic field in the equatorial plane. Immediately before the onset ( $T=56 \mathrm{~min}$ ), the plasma pressure is slightly concentrated near midnight, and the inner magnetosphere $(<7 R e)$ is filled with positive $E_{y}$ (red color). Immediately after the onset ( $T=58 \mathrm{~min}$ ), the plasma pressure is suddenly increased near midnight, the magnetic field also increases near midnight, indicating that the dipolarization process proceeds [Tanaka et al., 2010]. About $17 \mathrm{~min}$ after the onset ( $T=74 \mathrm{~min}$ ), the plasma pressure spreads dawnward and duskward, and the duskdawn electric field almost vanishes. The 

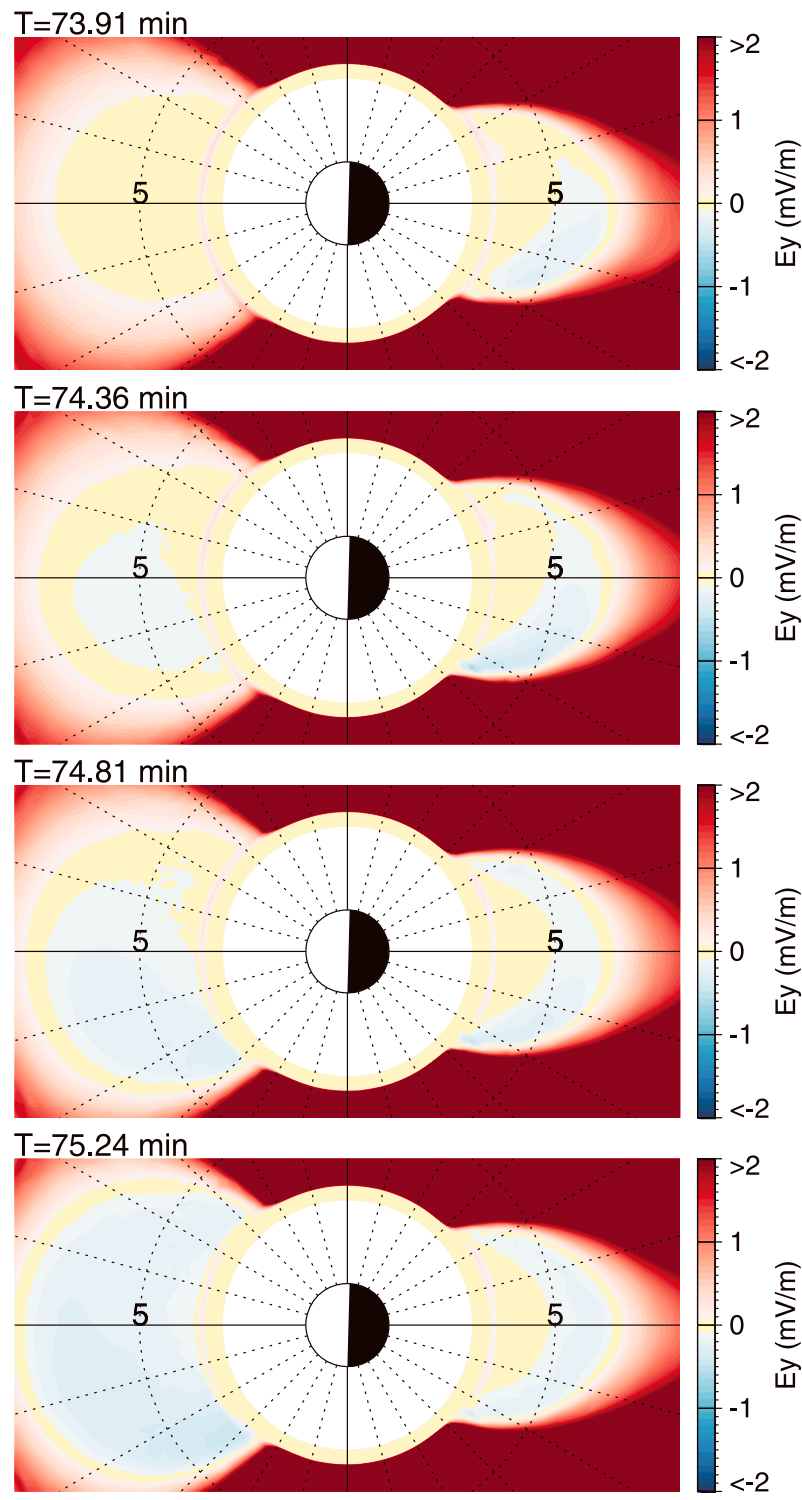

Figure 9. The $Y$ component of the electric field in the noon-midnight meridian at $74.36,74.81$, and $75.24 \mathrm{~min}$.

appear after a substorm onset under constant southward IMF. This may answer the first question as to why the westward EEJ (CEJ) occurs immediately after a substorm onset without apparent northward turning of the IMF. The mechanism is essentially the same as that responsible for SAID [e.g., Anderson et al., 1993]. Anderson et al. [1993] explained the separation of the two boundaries (the equatorward boundary of the auroral region and the equatorward boundary of the Region 2 current) in terms of different drift trajectories of hot ions and electrons originating from the nightside plasma sheet [e.g., Ejiri et al., 1980]. On the duskside, the inner edge of the hot electrons is located radially outward of the inner edge of the hot ions, which generates the separation of the two boundaries because hot electrons are responsible for the diffuse aurora (high-conductivity region), and hot ions are responsible for the Region 2 current. According to the global MHD simulation, the Region 2 current tends to flow into the ionosphere a few degrees lower than the equatorward boundary of the auroral region (high-pressure region), as shown in Figure 7. In addition to the different drift trajectories of ions and electrons, the deflection of current lines contributes to the separation of the boundaries.

When the overshielding condition is established in the inner magnetosphere, the plasma moves antisunward in the inner magnetosphere, thereby interrupting the earthward flow from the tail region as indicated by 


\section{AGU Journal of Geophysical Research: Space Physics 10.1002/2014JA020065}
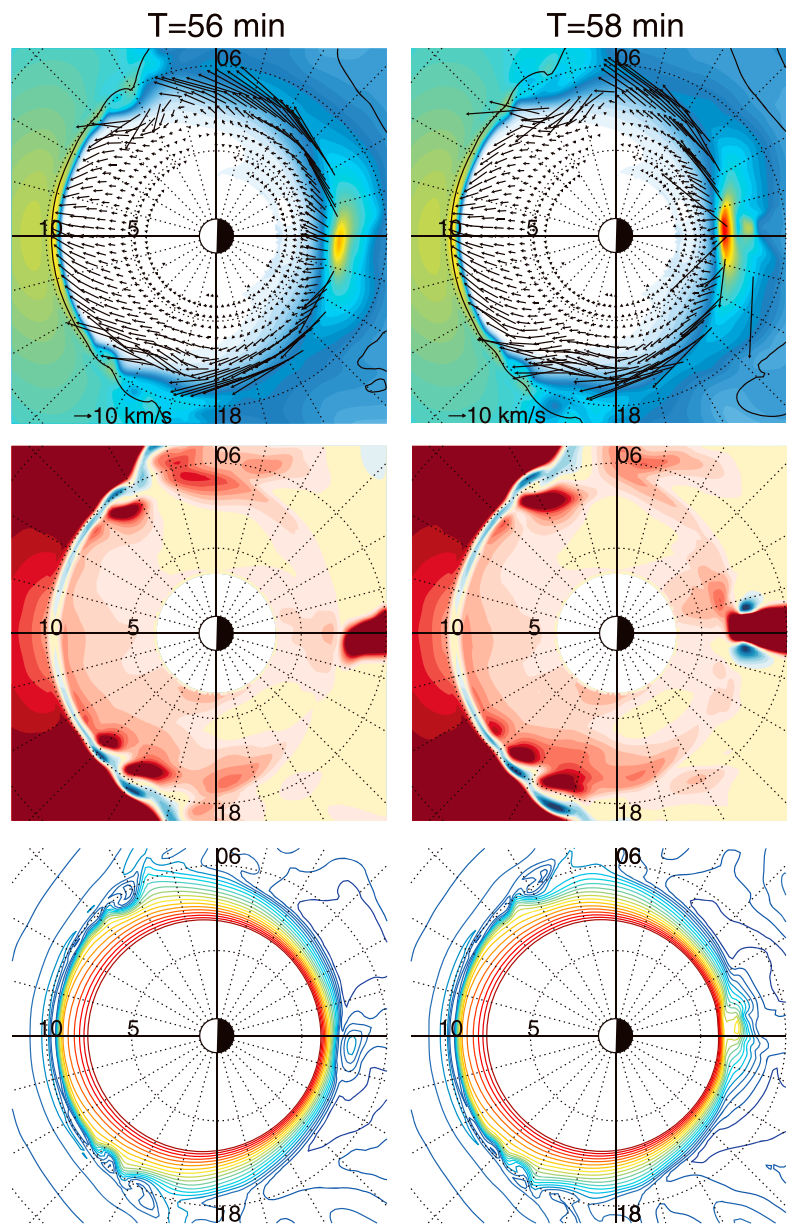
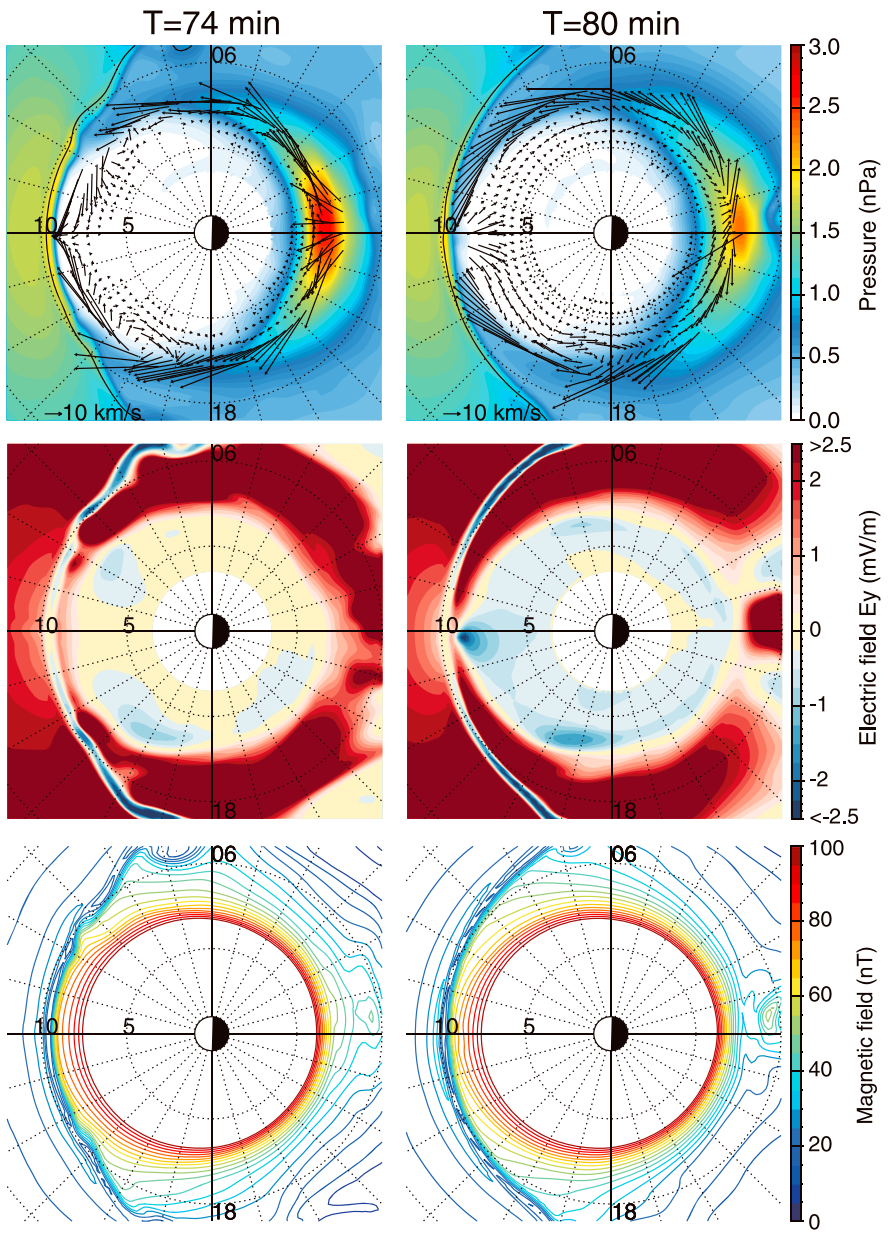

Figure 10. (top) The plasma pressure, (middle) the $Y$ component of the electric field, and (bottom) the intensity of the magnetic field in the equatorial plane. The Sun is to the left. In Figure 10 (top and middle), the solid contour indicates zero value of Bz. In Figure 10 (top), arrows indicate the plasma flow velocity.

arrows in Figure 10 (top). The interruption of the earthward flow may cause the plasma pressure to remain high, probably elongating the period of the CEJ. In other words, the overshielding condition may in part sustain the generation mechanism of the overshielding condition. In order to fully understand this selfsustained feature, we need to incorporate the plasma transport by the grad-B and curvature drifts into the global MHD simulation because high-energy ions tend to drift westward regardless of the electric field.

The intensity and polarity of the EEJ depend largely on the ionospheric conductivity in the region wherein the Region 2 current flows. We have not solved kinetic equations of energetic electrons, but it may be reasonable to consider, as a zeroth-order approximation, that the auroral conductivity depending on the plasma pressure

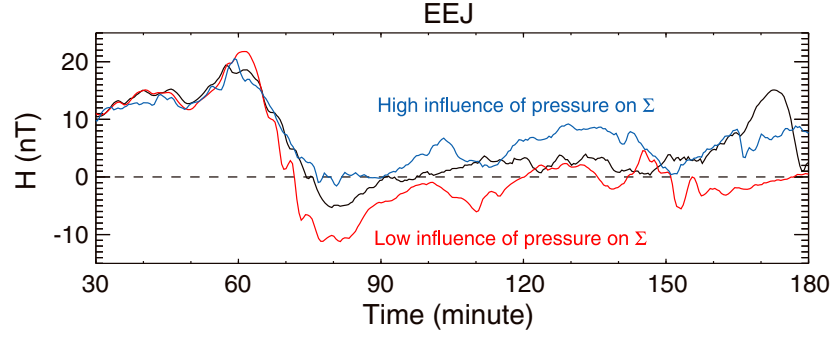

Figure 11. $H$ component of the ground magnetic field at noon at 0 MLAT (EEJ) in the cases that the dependence of the ionospheric conductivity on the plasma pressure is halved (red line) and doubled (blue line). is associated with the diffuse aurora. If so, the diffuse aurora would form an important factor in the generation of the overshielding condition because the diffuse aurora is coincident with the downward Region 2 current [e.g., Lopez et al., 1991]. This may answer the second question as to what determines the polarity of the EEJ during the substorms.

In general, satellite observations have shown that the direction of the 
magnetospheric convection is sunward in the inner magnetosphere [Baumjohann et al., 1985; Mcllwain, 1986; Matsui et al., 2004, 2013]. The dawn-dusk electric field plays an important role in the formation of the plasmapause [e.g., Nishida, 1966; Grebowsky, 1970; Chen et al., 1975] and the accumulation of hot ions, namely, the storm-time ring current [e.g., Chen, 1970; Smith and Hoffman, 1974; Grebowsky and Chen, 1975; Kivelson, 1976; Ejiri, 1978; Ejiri et al., 1978, 1980; Lee et al., 1983; Fok et al., 1996; Kozyra et al., 1998a; Ebihara and Ejiri, 2000; Liemohn et al., 2002]. Goldstein et al. [2002] demonstrated that the overshielding condition driven by northward turning of the IMF could have resulted in the evolution of the shoulder of the plasmapause. The overshielding condition would also influence the evolution of the ring current. When a substorm occurs during the main phase of the storm, the overshielding condition can impede the development of the ring current even though the southward IMF is prolonged. This may explain the observation that the SYM- $H$ index does not show any significant development after a substorm onset [lyemori and Rao, 1996]. Of course, the situation would not be so simple because of contribution from the tail current [Ohtani et al., 2001]. Further studies are required to investigate the development of the ring current in the overshielding condition in terms of storm-substorm relationships.

\section{Conclusion}

We demonstrated that the overshielding condition can be achieved after substorm onset for constant solar wind and IMF. The overshielding condition seems to appear first in the ionosphere, followed by its appearance in the magnetosphere. The leading mechanism is as follows. (1) Near the substorm onset, a highpressure region is formed in the inner magnetosphere on the nightside, generating Region 2 currents. (2) The Region 2 currents are deflected by the perpendicular diamagnetic current (ring current), and they flow into and out of the low-conductivity ionosphere. (3) A dusk-dawn electric field is generated in the ionosphere. (4) The dusk-dawn electric field propagates to the magnetosphere as shear Alfvén waves. (5) The inner magnetosphere is completely subject to the overshielding condition. The ground magnetic disturbances at the polar cap, auroral region, subauroral region, and magnetic equator are consistent with observations. The intensity and polarity of the equatorial electrojet depend largely on the ionospheric conductivity, so that the overshielding condition might not always appear after a substorm onset. We believe that our findings can significantly contribute to the understanding of storm-substorm relationship and overall transport of charged particles trapped in the inner magnetosphere.

Acknowledgments

We thank Shigeru Fujita and Kumiko K. Hashimoto for fruitful comments and discussion. The computer simulation was performed on the KDK computer system at Research Institute for Sustainable Humanosphere, Kyoto University. This study was supported by KAKENHI, Grant-in-Aid for Scientific Research (B) 24340119. The simulation data are available upon request.

Michael Liemohn thanks two reviewers for their assistance in evaluating this paper.

\section{References}

Anderson, P. C., W. B. Hanson, R. A. Heelis, J. D. Craven, D. N. Baker, and L. A. Frank (1993), A proposed production model of rapid subauroral ion drifts and their relationship to substorm evolution, J. Geophys. Res., 98(A4), 6069-6078, doi:10.1029/92JA01975.

Anderson, P. C., D. L. Carpenter, K. Tsuruda, T. Mukai, and F. J. Rich (2001), Multisatellite observations of rapid subauroral ion drifts (SAID), J. Geophys. Res., 106(A12), 29,585-29,599, doi:10.1029/2001JA000128.

Axford, W. I., and C. O. Hines (1961), A unifying theory of high-latitude geophysical phenomena and geomagnetic storms, Can. J. Phys., 39, 1433-1464.

Baumjohann, W., G. Haerendel, and F. Melzner (1985), Magnetospheric convection observed between 0600 and 2100 LT: Variations with Kp J. Geophys. Res., 103, 393-398, doi:10.1029/JA090iA01p00393.

Blanc, M., and A. Richmond (1980), The ionospheric disturbance dynamo, J. Geophys. Res., 85(A4), 1669-1686, doi:10.1029/JA085iA04p01669.

Chapman, S. (1951), The equatorial electrojet as detected from the abnormal electric current distribution above Huancayo, Peru, and elsewhere, Archiv. Meteorol. Geophys. Bioklimatol. Ser. A, 4(1), 368-390.

Chen, A. J. (1970), Penetration of low-energy protons deep into the magnetosphere, J. Geophys. Res., 75(13), 2458-2467, doi:10.1029/ JA075i013p02458.

Chen, A. J., J. M. Grebowsky, and H. A. Taylor Jr. (1975), Dynamics of mid-latitude light ion trough and plasma tails, J. Geophys. Res., 80(7), 968-976, doi:10.1029/JA080i007p00968.

Davis, T. N., and M. Sugiura (1966), Auroral electrojet activity index AE and its universal time variations, J. Geophys. Res., 71(3), 785-801, doi:10.1029/JZ071i003p00785.

Ebihara, Y., and M. Ejiri (2000), Simulation study on fundamental properties of the storm-time ring current, J. Geophys. Res., 105(A7), 15,843-15,859, doi:10.1029/1999JA900493.

Ebihara, Y., N. Nishitani, T. Kikuchi, T. Ogawa, K. Hosokawa, and M.-C. Fok (2008), Two-dimensional observations of overshielding during a magnetic storm by the Super Dual Auroral Radar Network (SuperDARN) Hokkaido radar, J. Geophys. Res., 113, A01213, doi:10.1029/ 2007JA012641.

Egedal, J. (1947), The magnetic diurnal variation of the horizontal force near the magnetic equator, Terr. Magn. Atmos. Electr., 52(4), 449-451, doi:10.1029/TE052i004p00449.

Ejiri, M. (1978), Trajectory traces of charged particles in the magnetosphere, J. Geophys. Res., 83(A10), 4798-4810, doi:10.1029/JA083iA10p04798.

Ejiri, M., R. A. Hoffman, and P. H. Smith (1978), The convection electric field model for the magnetosphere based on Explorer 45 observations, J. Geophys. Res., 83(A10), 4811-4815, doi:10.1029/JA083iA10p04811.

Ejiri, M., R. Hoffman, and P. H. Smith (1980), Energetic particle penetrations into the inner magnetosphere, J. Geophys. Res., 85(A2), 653-663, doi:10.1029/JA085iA02p00653. 
Fejer, B. G., C. A. Gonzales, D. T. Farley, and M. C. Kelley (1979), Equatorial electric fields during magnetically disturbed conditions: 1. The effect of the interplanetary magnetic field, J. Geophys. Res., 84, 5797-5802, doi:10.1029/JA084iA10p05797.

Fok, M.-C., T. E. Moore, J. U. Kozyra, G. C. Ho, and D. C. Hamilton (1995), Three-dimensional ring current decay model, J. Geophys. Res., 100(A6), 9619-9632, doi:10.1029/94JA03029.

Fok, M.-C., T. E. Moore, and M. E. Greenspan (1996), Ring current development during storm main phase, J. Geophys. Res., 101(A7), 15,311-15,322, doi:10.1029/96JA01274.

Foster, J. C., and W. J. Burke (2002), SAPS: A new categorization for sub-auroral electric fields, Eos. Trans. AGU, 83(36), 393-394, doi:10.1029/ 2002 EO000289.

Foster, J. C., and H. B. Vo (2002), Average characteristics and activity dependence of the subauroral polarization stream, J. Geophys. Res., 107(A12), 1475, doi:10.1029/2002JA009409.

Foster, J. C., J. M. Holt, R. C. Musgrove, and D. S. Evans (1986), lonospheric convection associated with discrete levels of particle precipitation, Geophys. Res. Lett., 13, 656-659, doi:10.1029/GL013i007p00656.

Fujita, S., T. Kikuchi, and T. Tanaka (2010), State transition of the magnetosphere-ionosphere compound system due to a northward turn of the interplanetary magnetic field revealed from a global magnetohydrodynamic simulation and formation of the overshielding potential, J. Geophys. Res., 115, A11210, doi:10.1029/2010JA015550.

Goldstein, J., R. W. Spiro, P. H. Reiff, R. A. Wolf, B. R. Sandel, J. W. Freeman, and R. L. Lambour (2002), IMF-driven overshielding electric field and the origin of the plasmaspheric shoulder of May 24, 2000, Geophys. Res. Lett., 29(16), 1819, doi:10.1029/2001GL014534.

Gonzales, C. A., M. C. Kelley, B. G. Fejer, J. F. Vickrey, and R. F. Woodman (1979), Equatorial electric fields during magnetically disturbed conditions: 2. Implications of simultaneous auroral and equatorial measurements, J. Geophys. Res., 84, 5803-5812, doi:10.1029/JA084iA10p05803.

Grebowsky, J. M. (1970), Model study of plasmapause motion, J. Geophys. Res., 75(22), 4329-4333, doi:10.1029/JA075i022p04329.

Grebowsky, J. M., and A. J. Chen (1975), Effects of convection electric field on the distribution of ring current type protons, Planet. Space Sci., $23,1045-1052$

Hashimoto, K. K., T. Kikuchi, S. Watari, and M. A. Abdu (2011), Polar-equatorial ionospheric currents driven by the region 2 field-aligned currents at the onset of substorms, J. Geophys. Res., 116, A09217, doi:10.1029/2011JA016442.

Heelis, R. A., J. K. Lowell, and R. W. Spiro (1982), A model of the high-latitude ionospheric convection pattern, J. Geophys. Res., 87(A8), 6339-6345, doi:10.1029/JA087iA08p06339.

Heppner, J. P., and N. C. Maynard (1987), Empirical high-latitude electric field models, J. Geophys. Res., 92, 4467-4489, doi:10.1029/ JA092iA05p04467.

Hirono, M. (1950), On the influence of the Hall current to the electrical conductivity of the ionosphere, II, J. Geomagn. Geoelectr., 2, 113-120.

Hirono, M. (1952), A theory of diurnal magnetic variations in equatorial regions and conductivity of the ionosphere E region, J. Geomagn. Geoelectr., 4, 7-21.

Huang, C.-S., J. C. Foster, L. P. Goncharenko, G. D. Reeves, J. L. Chau, K. Yumoto, and K. Kitamura (2004), Variations of low-latitude geomagnetic fields and Dst index caused by magnetospheric substorms, J. Geophys. Res., 109, A05219, doi:10.1029/2003JA010334.

Huang, C.-S., J. C. Foster, and M. C. Kelley (2005), Long-duration penetration of the interplanetary electric field to the low-latitude ionosphere during the main phase of magnetic storms, J. Geophys. Res., 110, A11309, doi:10.1029/2005JA011202.

lijima, T., and T. A. Potemra (1976), The amplitude distribution of field-aligned currents at northern high latitudes observed by Triad, J. Geophys. Res., 81(13), 2165-2174, doi:10.1029/JA081i013p02165.

lyemori, T., and D. R. K. Rao (1996), Decay of the Dst field of geomagnetic disturbance after substorm onset and its implication to stormsubstorm relation, Ann. Geophys., 14, 608

Karlsson, T., G. T. Marklund, L. G. Blomberg, and A. Mälkki (1998), Subauroral electric fields observed by the Freja satellite: A statistical study, J. Geophys. Res., 103(A3), 4327-4341, doi:10.1029/97JA00333.

Kelley, M. C., B. G. Fejer, and C. A. Gonzales (1979), An explanation for anomalous equatorial ionospheric electric fields associated with a northward turning of the interplanetary magnetic field, Geophys. Res. Lett., 6, 301, doi:10.1029/GL006i004p00301.

Kikuchi, T. (2014), Transmission line model for the near-instantaneous transmission of the ionospheric electric field and currents to the equator, J. Geophys. Res. Space Physics, 119, 1131-1156, doi:10.1002/2013JA019515.

Kikuchi, T., and T. Araki (1979), Horizontal transmission of the polar electric field to the equator, J. Atmos. Sol. Terr. Phys., 41, 927-936, doi:10.1016/0021-9169(79)90094-1.

Kikuchi, T., H. Lühr, T. Kitamura, O. Saka, and K. Schlegel (1996), Direct penetration of the polar electric field to the equator during a DP2 event as detected by the auroral and equatorial magnetometer chains and the EISCAT radar, J. Geophys. Res., 101, 17,161-17,173, doi:10.1029/ 96JA01299.

Kikuchi, T., M. Pinnock, A. Rodger, H. Lühr, T. Kitamura, H. Tachihara, M. Watanabe, N. Sato, and M. Ruohoniemi (2000a), Global evolution of a substorm-associated DP 2 current system observed by SuperDARN and magnetometers, Adv. Space Res., 26, 121.

Kikuchi, T., H. Lühr, K. Schlegel, H. Tachihara, M. Shinohara, and T.-I. Kitamura (2000b), Penetration of auroral electric fields to the equator during a substorm, J. Geophys. Res., 105, 23,251, doi:10.1029/2000JA900016.

Kikuchi, T., K. K. Hashimoto, T.-I. Kitamura, H. Tachihara, and B. Fejer (2003), Equatorial counterelectrojets during substorms, J. Geophys. Res., 108(A11), 1406, doi:10.1029/2003JA009915.

Kikuchi, T., Y. Ebihara, K. K. Hashimoto, R. Kataoka, T. Hori, S. Watari, and N. Nishitani (2010), Penetration of the convection and overshielding electric fields to the equatorial ionosphere during a quasiperiodic DP 2 geomagnetic fluctuation event, J. Geophys. Res., 115, A05209, doi:10.1029/2008JA013948.

Kivelson, M. G. (1976), Magnetospheric electric fields and their variation with geomagnetic activity, Rev. Geophys., 14(2), 189-197, doi:10.1029/RG014i002p00189.

Kobea, A. T., C. Amory-Mazaudier, J. M. Do, H. Luehr, E. Hougninou, J. Vassal, E. Blanc, and J. J. Curto (1998), Equatorial electrojet as part of the global circuit: A case-study from the IEEY, Ann. Geophys., 16, 698-710, doi:10.1007/s00585-998-0698-1.

Kobea, A. T., A. D. Richmond, B. A. Emery, C. Peymirat, H. Luehr, T. Moretto, M. Hairston, and C. Amory-Mazaudier (2000), Electrodynamic coupling of high and low latitudes: Observations on May 27, 1993, J. Geophys. Res., 105, 22,979-22,989, doi:10.1029/2000JA000058.

Kozyra, J. U., V. K. Jordanova, J. E. Borovsky, M. F. Thomsen, D. J. Knipp, D. S. Evans, D. J. McComas, and T. E. Cayton (1998a), Effects of a highdensity plasma sheet on ring current development during the November 2-6, 1993, magnetic storm, J. Geophys. Res., 103(A11), 26,285-26,305, doi:10.1029/98JA01964.

Kozyra, J. U., M.-C. Fok, E. R. Sanchez, D. S. Evans, D. C. Hamilton, and A. F. Nagy (1998b), The role of precipitation losses in producing the rapid early recovery phase of the Great Magnetic Storm of February 1986, J. Geophys. Res., 103(A4), 6801-6814, doi:10.1029/97JA03330.

Lee, L. C., G. Corrick, and S.I. Akasofu (1983), On the ring current energy injection rate, Planet. Space Sci., 31, 901. 
Liemohn, M. W., J. U. Kozyra, V. K. Jordanova, G. V. Khazanov, M. F. Thomsen, and T. E. Cayton (1999), Analysis of early phase ring current recovery mechanisms during geomagnetic storms, Geophys. Res. Lett., 26, 2845-2848, doi:10.1029/1999GL900611.

Liemohn, M. W., J. U. Kozyra, M. F. Thomsen, J. L. Roeder, G. Lu, J. E. Borovsky, and T. E. Cayton (2001), Dominant role of the asymmetric ring current in producing the stormtime Dst*, J. Geophys. Res., 106(A6), 10,883-10,904, doi:10.1029/2000JA000326.

Liemohn, M. W., J. U. Kozyra, C. R. Clauer, G. V. Khazanov, and M. F. Thomsen (2002), Adiabatic energization in the ring current and its relation to other source and loss terms, J. Geophys. Res., 107(A4), 1045, doi:10.1029/2001JA000243.

Lopez, R. E., H. E. Spence, and C.-I. Meng (1991), DMSP F7 observations of a substorm field-aligned current, J. Geophys. Res., 96(A11), 19,409-19,415, doi:10.1029/91JA01984.

Lui, A. T. Y. (2003), Inner magnetospheric plasma pressure distribution and its local time asymmetry, Geophys. Res. Lett., 30(16), 1846, doi:10.1029/2003GL017596.

Maekawa, K., and H. Maeda (1978), Electric fields in the ionosphere produced by polar field-aligned currents, Nature, 273, 649-650.

Matsui, H., V. K. Jordanova, J. M. Quinn, R. B. Torbert, and G. Paschmann (2004), Derivation of electric potential patterns in the inner magnetosphere from Cluster EDI data: Initial results, J. Geophys. Res., 109, A10202, doi:10.1029/2003JA010319.

Matsui, H., R. B. Torbert, H. E. Spence, Y. V. Khotyaintsev, and P.-A. Lindqvist (2013), Revision of empirical electric field modeling in the inner magnetosphere using Cluster data, J. Geophys. Res. Space Physics, 118, 4119-4134, doi:10.1002/jgra.50373.

Mcllwain, C. E. (1986), A Kp dependent equatorial electric field model, Adv. Space Res., 6(3), 187-197.

Moriguchi, T., A. Nakamizo, T. Tanaka, T. Obara, and H. Shimazu (2008), Current systems in the Jovian magnetosphere, J. Geophys. Res., 113, A05204, doi:10.1029/2007JA012751.

Nishida, A. (1966), Formation of plasmapause, or magnetospheric plasma knee, by the combined action of magnetospheric convection and plasma escape from the tail, J. Geophys. Res., 71(23), 5669-5679, doi:10.1029/JZ071i023p05669.

Nishida, A. (1968), Coherence of geomagnetic DP 2 fluctuations with interplanetary magnetic variations, J. Geophys. Res., 73(17), 5549-5559, doi:10.1029/JA073i017p05549.

Nishida, A., and J. A. Jacobs (1962), World-wide changes in the geomagnetic field, J. Geophys. Res., 67(2), 525-540, doi:10.1029/ JZ067i002p00525.

Nishimura, Y., T. Kikuchi, J. Wygant, A. Shinbori, T. Ono, A. Matsuoka, T. Nagatsuma, and D. Brautigam (2009), Response of convection electric fields in the magnetosphere to IMF orientation change, J. Geophys. Res., 114, A09206, doi:10.1029/2009JA014277.

Nopper, R. W., and R. L. Carovillano (1978), Polar equatorial coupling during magnetically active periods, Geophys. Res. Lett., 5, 699, doi:10.1029/GL005i008p00699.

Ohtani, S., M. Nosé, G. Rostoker, H. Singer, A. T. Y. Lui, and M. Nakamura (2001), Storm-substorm relationship: Contribution of the tail current to Dst, J. Geophys. Res., 106(A10), 21,199-21,209, doi:10.1029/2000JA000400.

Ohtani, S., T. Uozumi, H. Kawano, A. Yoshikawa, H. Utada, T. Nagatsuma, and K. Yumoto (2013), The response of the dayside equatorial electrojet to step-like changes of IMF BZ, J. Geophys. Res. Space Physics, 118, 3637-3646, doi:10.1002/jgra.50318.

Papitashvili, V. O., B. A. Belov, D. S. Faermark, Y. I. Feldstein, S. A. Golyshev, L. I. Gromova, and A. E. Levitin (1994), Electric potential patterns in the northern and southern polar regions parameterized by the interplanetary magnetic field, J. Geophys. Res., 99, 13,251-13,262, doi:10.1029/94JA00822.

Rich, F. J., and M. Hairston (1994), Large-scale convection patterns observed by DMSP, J. Geophys. Res., 99, 3827, doi:10.1029/93JA03296.

Richmond, A. D., and S. Matsushita (1975), Thermospheric response to a magnetic substorm, J. Geophys. Res., 80(19), 2839-2850, doi:10.1029/ JA080i019p02839.

Ruohoniemi, J. M., and R. A. Greenwald (1996), Statistical patterns of high-latitude convection obtained from Goose Bay HF radar observations, J. Geophys. Res., 101, 21,743, doi:10.1029/96JA01584.

Sastri, J. H., M. A. Abdu, and J. H. A. Sobral (1997), Response of equatorial ionosphere to episodes of asymmetric ring current activity, Ann Geophys., 15, 1316-1323, doi:10.1007/s00585-997-1316-3.

Sastri, J. H., J. V. S. V. Rao, D. R. K. Rao, and B. M. Pathan (2001), Daytime equatorial geomagnetic H field response to the growth phase and expansion phase onset of isolated substorms: Case studies and their implications, J. Geophys. Res., 106, 29,925-29,933, doi:10.1029/ 2001JA900120.

Sastri, J. H., Y. Kamide, and K. Yumoto (2003), Signatures for magnetospheric substorms in the geomagnetic field of dayside equatorial region: Origin of the ionospheric component, J. Geophys. Res., 108(A10), 1375, doi:10.1029/2003JA009962.

Smith, P. H., and R. A. Hoffman (1974), Direct observation in the dusk hours of the characteristics of the storm time ring current particles during the beginning of magnetic storms, J. Geophys. Res., 79, 966-967, doi:10.1029/JA079i007p00966.

Somayajulu, V. V., C. A. Reddy, and K. S. Viswanathan (1987), Penetration of magnetospheric convective electric field to the equatorial ionosphere during the substorm of March 22, 1979, Geophys. Res. Lett., 14, 876-879, doi:10.1029/GL014i008p00876.

Spiro, R. W., R. A. Heelis, and W. B. Hanson (1979), Rapid subauroral ion drifts observed by Atmosphere Explorer C, Geophys. Res. Lett., 6 , 657-660, doi:10.1029/GL006i008p00657.

Spiro, R. W., R. A. Wolf, and B. G. Fejer (1988), Penetration of high-latitude-electric-field effects to low latitudes during SUNDIAL 1984, Ann Geophys., 6, 39

Tanaka, T. (1994), Finite volume TVD scheme on an unstructured grid system for three-dimensional MHD simulation of inhomogeneous systems including strong background potential fields, J. Comput. Phys., 111, 381, doi:10.1006/jcph.1994.1071.

Tanaka, T. (1995), Generation mechanisms for magnetosphere-ionosphere current systems deduced from a three-dimensional MHD simulation of the solar wind-magnetosphere-ionosphere coupling processes, J. Geophys. Res., 100(A7), 12,057-12,074, doi:10.1029/95JA00419.

Tanaka, T. (2000a), The state transition model of the substorm onset, J. Geophys. Res., 105, 21,081, doi:10.1029/2000JA900061.

Tanaka, T. (2000b), Field-aligned current systems in the numerically simulated magnetosphere, in Magnetospheric Current Systems, Geophys. Monogr. Ser., vol. 118, edited by S. Ohtani et al., pp. 53-59, AGU, Washington, D. C.

Tanaka, T. (2007), Magnetosphere-ionosphere convection as a compound system, Space Sci. Rev., 133, 1, doi:10.1007/s11214-007-9168-4.

Tanaka, T., A. Nakamizo, A. Yoshikawa, S. Fujita, H. Shinagawa, H. Shimazu, T. Kikuchi, and K. K. Hashimoto (2010), Substorm convection and current system deduced from the global simulation, J. Geophys. Res., 115, A05220, doi:10.1029/2009JA014676.

Tsunomura, S. (1999), Numerical analysis of global ionospheric current system including the effect of equatorial enhancement, Ann. Geophys., 17, 692-706.

Tsunomura, S., and T. Araki (1984), Numerical analysis of equatorial enhancement of geomagnetic sudden commencement, Planet. Space Sci., 32, 599-604.

Wei, Y., M. Hong, W. Wan, A. Du, Z. Pu, M. F. Thomsen, Z. Ren, and G. D. Reeves (2008), Coordinated observations of magnetospheric reconfiguration during an overshielding event, Geophys. Res. Lett., 35, L15109, doi:10.1029/2008GL033972. 
Wei, Y., et al. (2009), Westward ionospheric electric field perturbations on the dayside associated with substorm processes, J. Geophys. Res., 114, A12209, doi:10.1029/2009JA014445.

Weimer, D. R. (2001), An improved model of ionospheric electric potentials including substorm perturbations and application to the Geospace Environment Modeling November 24, 1996, event, J. Geophys. Res., 106(A1), 407-416, doi:10.1029/2000JA000604.

Zhang, J.-C., R. A. Wolf, R. W. Spiro, G. M. Erickson, S. and Sazykin, F. R. Toffoletto, and J. Yang (2009), Rice Convection Model simulation of the substorm-associated injection of an observed plasma bubble into the inner magnetosphere: 2 . Simulation results, J. Geophys. Res., 114, A08219, doi:10.1029/2009JA014131.

Zmuda, A. J., and J. C. Armstrong (1974), The diurnal flow pattern of field-aligned currents, J. Geophys. Res., 79(31), 4611-4619, doi:10.1029/ JA079i031p04611. 